\title{
$\bullet$ \\ IJCRR \\ Section: Healthcare \\ Diagnostic Accuracy of Clinical History for Detection of Acute Myocardial Infarction: A Cross-Sectional Study
}

Sci. Journal Impact

Factor: 6.1 (2018)

ICV: 90.90 (2018)

\author{
Gajanan V. Wasalwar' ${ }^{1}$, D. S. Wasnik ${ }^{2}$
}

'Former Professor of Medicine, Government Medical College, Chandrapur, M.S., India; ${ }^{2}$ Former Lecturer in Medicine Indira Gandhi Govt.

Medical College, Nagpur, M.S., India

\section{ABSTRACT}

Introduction: Acute myocardial infarction (AMI) is an important cause of admission in the intensive care unit in hospitals. AMI ranks very high in the differential diagnosis of acute chest pain because prompt diagnosis and early treatment can save a life, preserve left ventricular function, reduce complications and can also impact the quality of life.

Aim: Current study was done to evaluate the diagnostic accuracy of clinical history for detecting acute myocardial infarction compared to the reference standard.

Result: Our final dataset comprises of 450 patients (279 [62\%] men, 171 [38\%] women) ages 20 to 90 years. The prevalence of acute myocardial infarction was $41 \%$ (187 of $460,95 \% \mathrm{Cl} 37 \%$ to $46 \%$ ). Of the 450 patients, 47 (10\%) died during the hospital stay. Those who died were significantly older than those who survived (63.4 vs. 57.01 years). Patients with AMI were more likely to die (26\%; 38 of 147 ) compared to those without MI (9 of 263; $3 \%$ ).

Conclusion: Of the 187 patients with acute AMI, 145 (78\%) were assigned a discharge diagnosis of ST elevated myocardial infarction (STEMI) and 42 (22\%) were assigned a diagnosis of non-ST elevated myocardial infarction. A total of 34 of 145 (23\%) patients with STEMI died, compared to 4 of $42(10 \%)$ patients with non-STEMI. Even in a high prevalence setting, no sign or symptom exhibited by patients presenting with possible acute MI proved effective enough alone to rule in or out Acute Myocardial Infection (AMI).

Key Words: Acute myocardial infarction, STEMI, Clinical history, Intermittent, Pain, AMI.

\section{INTRODUCTION}

Despite advances in diagnosis, physicians miss up to $10 \%$ of AMI presenting with acute chest pain ${ }^{1,2,3}$. Conversely, a large proportion of people with chest pain who are admitted, do not turn out to AMI. According to the American Heart Association criteria, patients with proven AMI must receive thrombolysis within 30 minutes of their arrival to the hospital (door to needle time). To ensure that patients with AMI receive evidence-based therapies, it is important that AMI is ruled in or ruled out, quickly and accurately. No less important is to exclude other life-threatening conditions such as pulmonary embolism, tension pneumothorax and aortic dissection.

History and physical examination are key elements used by physicians to triage patients with acute chest pain ${ }^{4,5}$. Typically physicians take a quick but focused history (quality, site, intensity, radiation and aggravation of pain), note the presence or absence of risk factors (smoking, obesity, hypertension and diabetes) and perform a physical examination (vital signs, assessment of heart size, third heart sound and crackles) $)^{6,7,8}$. In the initial management of patients presenting with suspected MI, the history and physical examination help physicians decide which diagnostic tests to order (ECG, biomarkers of AMI, biomarkers, chest radiogram or endoscopy)or plan therapeutic interventions (aspirin, streptokinase or primary angioplasty).

\section{AIMS \& OBJECTIVES}

To evaluate the diagnostic accuracy of clinical history for detecting acute myocardial infarction compared to the reference standard.

\section{Corresponding Author:}

Dr. Gajanan V. Wasalwar, The former professor of Medicine, Government Medical College, Chandrapur, India Mob: 09822203717

ISSN: 2231-2196 (Print)

Received: 10.06 .2020
ISSN: 0975-5241 (Online)

Revised: 18.07 .2020
Accepted: 15.08 .2020
Published: 22.09 .2020 


\section{SUBJECTS AND METHODS}

We conducted this study in an intensive care unit (ICU) of the Department of Medicine. The Medicine department has an ICU (10 beds) and a step-down unit (18 beds). The ICU is equipped with ventilators, monitoring systems and electronic hospital information system. The hospital offers basic cardiac diagnostic and therapeutic facility but lacks set up for cardiac catheterization or cardio-vascular thoracic surgery and therefore cannot offer primary angioplasty to patients reporting within 90 minutes of AMI. This is a prospective crosssectional study in which consecutive patients with acute chest pain and possible ACS presenting to the intensive care unit were enrolled. Before we began the study, we formulated the research question, wrote research protocol, and obtained approval from the institutional research committee and a waiver for obtaining informed consent from the study participants.

We conducted this study according to the principles of the Declaration of Helsinki and after the study protocol was approved by the institutional ethics committee. The diagnosis of acute myocardial infarction was based on the criteria proposed by the World Health Organization (WHO). We summarized data with the mean and median as measures of central tendency and standard deviations and interquartile ranges as measures of spread for continuous variables.

\section{RESULTS}

We used STARD (Standards for Reporting Diagnostic Accuracy Study) guidelines to report this study. We screened patients, 30 years of age and older suspected to have acute myocardial infarction and admitted to the intensive care unit. The total number of patients presenting with acute chest pain and admitted to the intensive care unit were 481 . Out of which 31 were excluded due to death or incomplete data. So final study subjects were 450 . Out of which 187 had AMI \& 263 had chest pain other than AMI. Out of total 187 cases of AMI, 145 had ST-elevated myocardial infarction \& 42 had Non-ST- elevated myocardial infarction.

Thus, our final dataset comprises of 450 patients (279 [62\%] men, 171 [38\%] women) ages 20 to 90 years. The prevalence of acute myocardial infarction was $41 \%$ (187 of $460,95 \%$ CI $37 \%$ to $46 \%$ ). Of the 450 patients, 47 (10\%) died during the hospital stay. Those who died were significantly older than those who survived (63.4 vs. 57.01 years). Patients with AMI were more likely to die (26\%; 38 of 147) compared to those without MI (9 of 263; 3\%). Of the 187 patients with acute AMI, 145 (78\%) were assigned a discharge diagnosis of ST elevated myocardial infarction (STEMI) and 42 (22\%) were assigned a diagnosis of non-ST elevated myocardial infarction. A total of 34 of $145(23 \%)$ patients with STEMI died, compared to 4 of $42(10 \%)$ patients with non-STEMI.

After analysis of the character of pain during acute myocardial infarction, we found out that squeezing or gastric type of pain are good predictors of acute myocardial infarction. While sharp/ stabbing/ burning pain is poor predictors. In maximum cases of acute myocardial infarction, the location of the pain is substernal.

\begin{tabular}{|c|c|c|c|c|c|}
\hline Symptoms & & $\begin{array}{l}\text { With } \\
\text { AMI }\end{array}$ & $\begin{array}{l}\text { Without } \\
\text { AMI }\end{array}$ & Total & $\begin{array}{c}\text { P- } \\
\text { value }\end{array}$ \\
\hline \multicolumn{6}{|c|}{ Character of pain } \\
\hline \multirow{2}{*}{ Squeezing } & Present & 110 & 49 & 159 & \multirow{2}{*}{0.001} \\
\hline & Absent & 77 & 214 & 291 & \\
\hline \multirow{2}{*}{ Heavy } & Present & 57 & 109 & 166 & \multirow{2}{*}{0.018} \\
\hline & Absent & 130 & 154 & 284 & \\
\hline \multirow{2}{*}{ Burning } & Present & 26 & 48 & 74 & \multirow{2}{*}{0.220} \\
\hline & Absent & 161 & 215 & 376 & \\
\hline \multirow{2}{*}{ Gastric } & Present & 5 & 31 & 36 & \multirow[t]{2}{*}{$<0.001$} \\
\hline & Absent & 182 & 232 & 414 & \\
\hline \multirow{2}{*}{ Sharp/stabbing } & Present & 67 & 92 & 159 & \multirow{2}{*}{0.853} \\
\hline & Absent & 120 & 171 & 291 & \\
\hline \multicolumn{6}{|c|}{ Location of pain } \\
\hline \multirow{2}{*}{ substernal } & Present & 103 & 107 & 210 & \multirow{2}{*}{0.003} \\
\hline & Absent & 84 & 156 & 240 & \\
\hline
\end{tabular}

In most cases, the pain radiated to right arm or both arms or individual shoulder or both shoulders. While in a maximum of the cases, that pain is of intermittent type. While regarding frequency, there was no specific relation. In all the cases it was either first episode or had some history of the episode.

\section{Table 2: Diagnostic accuracy of history (radiation of pain, its pattern $\&$ frequency).

$\begin{array}{lll}\text { Symptoms } & \text { With Without Total P-value }\end{array}$

\section{Radiation}

Left arm

Right arm

nostic acc
Present
Absent
Present
Absent
Present
Absent
Present
Absent
Present
Absent
Present
Absent

Both arms

$\begin{array}{lll}\text { Present } & 27 & 24 \\ \text { Absent } & 160 & 239 \\ \text { Present } & 18 & 5\end{array}$
51 Present 18

Left shoulder 169

Present 37

Absent

37

Present 30

Absent


Table 2: (Continued)

\begin{tabular}{|c|c|c|c|c|c|}
\hline \multicolumn{2}{|l|}{ Symptoms } & $\begin{array}{l}\text { With } \\
\text { AMI }\end{array}$ & $\begin{array}{l}\text { Without } \\
\text { AMI }\end{array}$ & Total & P-value \\
\hline \multirow{2}{*}{ Right shoulder } & Present & 16 & 5 & 21 & \multirow{2}{*}{0.001} \\
\hline & Absent & 171 & 258 & 429 & \\
\hline \multirow{2}{*}{ Both shoulders } & Present & 49 & 36 & 85 & \multirow{2}{*}{0.001} \\
\hline & Absent & 138 & 227 & 365 & \\
\hline \multirow{2}{*}{ All over chest } & Present & 61 & 86 & 147 & \multirow{2}{*}{0.986} \\
\hline & Absent & 126 & 177 & 303 & \\
\hline \multicolumn{6}{|l|}{ Pattern } \\
\hline \multirow{2}{*}{ Intermittent } & Present & 49 & 104 & 153 & \multirow{2}{*}{0.003} \\
\hline & Absent & 138 & 159 & 297 & \\
\hline \multirow{2}{*}{ Continuous } & Present & 134 & 158 & 292 & \multirow{2}{*}{0.011} \\
\hline & Absent & 53 & 105 & 158 & \\
\hline \multicolumn{6}{|c|}{ Frequency of pain } \\
\hline \multirow{2}{*}{ First Pain, ever } & Present & 144 & 155 & 299 & \multirow{2}{*}{$<0.001$} \\
\hline & Absent & 43 & 108 & 151 & \\
\hline \multirow{2}{*}{ Previous pain } & Present & 42 & 106 & 148 & \multirow{2}{*}{$<0.001$} \\
\hline & Absent & 145 & 157 & 302 & \\
\hline
\end{tabular}

In most of the cases, the episode was aggravated by exertion \& coughing, while it was relieved by nitroglycerine or rest or by taking an analgesic. There was no significant effect of taking antacids.

Table 3: Diagnostic accuracy of history (aggravating \& relieving factors).

\begin{tabular}{|c|c|c|c|c|c|}
\hline \multicolumn{2}{|l|}{ Symptoms } & $\begin{array}{l}\text { With } \\
\text { AMI }\end{array}$ & $\begin{array}{c}\text { Without } \\
\text { AMI }\end{array}$ & Total & P-value \\
\hline \multicolumn{6}{|c|}{ Aggravating factors } \\
\hline \multirow{2}{*}{ Exertion } & Present & 51 & 113 & 164 & \multirow{2}{*}{0.001} \\
\hline & Absent & 136 & 150 & 286 & \\
\hline \multirow{2}{*}{ Emotion } & Present & 11 & 15 & 26 & \multirow{2}{*}{0.936} \\
\hline & Absent & 176 & 248 & 424 & \\
\hline \multirow{2}{*}{ Coughing } & Present & 9 & 47 & 56 & \multirow{2}{*}{$<0.001$} \\
\hline & Absent & 177 & 216 & 293 & \\
\hline \multicolumn{6}{|c|}{ Relieving factors } \\
\hline \multirow{2}{*}{ Nitroglycerine } & Present & 118 & 94 & 212 & \multirow{2}{*}{$<0.001$} \\
\hline & Absent & 69 & 169 & 238 & \\
\hline \multirow{2}{*}{ Antacids } & Present & 7 & 16 & 23 & \multirow{2}{*}{0.263} \\
\hline & Absent & 180 & 246 & 426 & \\
\hline \multirow{2}{*}{ Rest } & Present & 32 & 88 & 120 & \multirow{2}{*}{$<0.001$} \\
\hline & Absent & 155 & 175 & 330 & \\
\hline \multirow{2}{*}{ Analgesics } & Present & 2 & 40 & 42 & \multirow{2}{*}{$<0.001$} \\
\hline & Absent & 185 & 223 & 408 & \\
\hline
\end{tabular}

Along with chest pain, most of the patients experienced sweating \& few experienced dyspnea. Rest of the factors like associated nausea, vomiting, palpitation, giddiness etc are not of much having predictive value.

Table 4: Diagnostic accuracy of history (associated factors).

\begin{tabular}{|c|c|c|c|c|c|}
\hline \multicolumn{2}{|l|}{ Symptoms } & $\begin{array}{l}\text { With } \\
\text { AMI }\end{array}$ & $\begin{array}{c}\text { Without } \\
\text { AMI }\end{array}$ & Total & P-value \\
\hline \multicolumn{6}{|c|}{ Associated factors } \\
\hline \multirow{2}{*}{ Nausea } & Present & 35 & 53 & 88 & \multirow{2}{*}{0.705} \\
\hline & Absent & 152 & 210 & 362 & \\
\hline \multirow{2}{*}{ Vomiting } & Present & 35 & 42 & 77 & \multirow{2}{*}{0.446} \\
\hline & Absent & 152 & 221 & 373 & \\
\hline \multirow{2}{*}{ Palpitation } & Present & 61 & 77 & 138 & \multirow{2}{*}{0.449} \\
\hline & Absent & 126 & 186 & 312 & \\
\hline \multirow{2}{*}{ Sweating } & Present & 118 & 83 & 201 & \multirow{2}{*}{$<0.001$} \\
\hline & Absent & 69 & 180 & 249 & \\
\hline \multirow{2}{*}{ Giddiness } & Present & 29 & 54 & 83 & \multirow{2}{*}{0.176} \\
\hline & Absent & 158 & 209 & 367 & \\
\hline \multirow{2}{*}{ Dyspnoea } & Present & 47 & 91 & 138 & \multirow{2}{*}{0.032} \\
\hline & Absent & 140 & 172 & 312 & \\
\hline
\end{tabular}

When we consider history, hypertension and angina are the most important findings which can't be missed. While findings like diabetes, Hyperlipidaemia or smoking are of not much predictive value. While the family history of coronary heart disease or diabetes also having not much predictive value.

Table 5: Diagnostic accuracy of history (personal \& family history)

$\begin{array}{ll}\text { Symptoms } & \text { With Without Total P-value } \\ \text { AMI AMI }\end{array}$

Personal history

Angina

Present $\quad 27 \quad 57 \quad 84$

Diabetes

Absent $160 \quad 206$

84
366

0.052

Diabetes

Present 4960

Hypertension

Absent $138 \quad 203$

109

41

0.408

Hypertension

Present $26 \quad 55$

Hyperlipidaemia

Absent $\quad 161 \quad 208$

81

$208-369$

0.056

$\begin{array}{llll}\text { Present } & 4 & 3 & 7\end{array}$

Smoking

Absent $183 \quad 260$

443

0.399

Present $26 \quad 45$

Absent $\quad 161 \quad 218$

71

379

0.358

Family history

Coronary heart

disease

Diabetes

$\begin{array}{lllll}\text { Present } & 8 & 9 & 17 & 0.639 \\ \text { Absent } & 179 & 254 & 433 & \\ \text { Present } & 5 & 12 & 17 & \\ \text { Absent } & 182 & 251 & 433 & 0.300\end{array}$


Table 6: Is this a heart attack?

\begin{tabular}{lccccc} 
Symptoms & & $\begin{array}{c}\text { With } \\
\text { AMI }\end{array}$ & $\begin{array}{c}\text { Without } \\
\text { AMI }\end{array}$ & Total & P-value \\
$\begin{array}{l}\text { Is this a heart } \\
\text { attack? }\end{array}$ & Present & 92 & 76 & 168 & 0.001 \\
& Absent & 95 & 186 & 281 & \\
\hline
\end{tabular}

After analysis, following features of history emerged as independent predictors of AMI: crushing chest pain, pain radiating to the right arm, heavy chest, burning character of chest pain, male sex, sweating, apprehension, pain relieved with nitroglycerine, and pain radiating to both shoulders.

\section{DISCUSSION}

The main finding of our study which is explicitly demonstrated in the table $(1,2,3,4,5)$, clearly demonstrate that in patients presenting with-and admitted because of- acute chest pain, the presence of any of the following characteristics of pain increased the likelihood of AMI: male sex, patients perceiving a sense of impending doom, chest pain radiating to either right arm, or both shoulders, squeezing chest pain, burning pain and so on. Fourteen studies ${ }^{4,9,12-17}$ have assessed the accuracy of the medical history, physical examination, and ECG in the diagnosis of acute $\mathrm{MI}^{9,13,14,15,16}$. In this study, we compare and contrast our results with those from the studies that enrolled patients with suspected AMI in the ICU setting. ${ }^{18,19}$.

The diagnosis of AMI in the setting of acute chest pain is a challenging task. Although doctors and patients believe that classic ischemic chest pain chooses the substernal or left chest area, few studies have assessed whether specific chest pain locations predict AMI or ACS. The word chest pain radiation typically refers to pain that originates in the chest but spreads to places other than the chest, such as the neck, back or arm. Ischemic chest pain is classically characterized as radiating from the chest through one arm or both, a lesson supported by several studies. ${ }^{9,12,17}$ Physicians teach that Chest pain that is pleuritic, positional, or reproducible with chest wall palpation is unlikely to be due to acute MI. This teaching is supported by a systematic review ${ }^{5}$ that showed that clinical features that decrease the probability of MI in patients presenting with acute chest pain are pleuritic chest pain.

There is a well-known correlation between exercise and angina. However, there is a less direct link between exercise and AMI. Mittleman et al. ${ }^{11}$ reported that AMI patients were more likely to report heavy exertion in the hour preceding their event, confirming an association between exercise and AMI. Several studies ${ }^{9,12,14,15}$ have examined the ability of associated symptoms such as nausea, vomiting and diaphoresis to predict AMI. Two meta-analyses show that nausea or vomiting and diaphoresis aid in the diagnosis of AMI. However, in the study by Goodacre et al. ${ }^{10}$ vomiting and diaphoresis failed to retain their place in the final multivariate logistic regression model.

\section{CONCLUSION}

Based on our study result shoed in table no 6 , out of the 187 patients with acute AMI, 145 (78\%) were assigned a discharge diagnosis of ST elevated myocardial infarction (STEMI) and 42 (22\%) were assigned a diagnosis of non-ST elevated myocardial infarction. A total of 34 of $145(23 \%)$ patients with STEMI died, compared to 4 of $42(10 \%)$ patients with non-STEMI. Even in a high prevalence setting, no sign or symptom exhibited by patients presenting with possible acute MI proved effective enough alone to rule in or out AMI.

Acknowledgement: Authors acknowledge the immense help received from the scholars whose articles are cited and included in references of this manuscript. The authors are also grateful to authors / editors / publishers of all those articles, journals and books from where the literature for this article has been reviewed and discussed.

\section{Conflict of Interest: Nil}

\section{Source of Funding: Nil}

\section{REFERENCES}

1. Lee $\mathrm{T}$ et al. Acute chest pain in the emergency room. Identification and examination of low-risk patients. Arch Intern Med. 1985;145(1):65-9.

2. Tierney $\mathrm{W}$ et al. Predictors of myocardial infarction in emergency room patients. Crit Care Med. 1985;13(7):526-31.

3. Rouan $\mathrm{G}$ et al. Clinical characteristics and outcome of acute myocardial infarction in patients with initially normal or nonspecific electrocardiograms (a report from the Multicenter Chest Pain Study). Am J Cardiol. 1989;64(18):1087-92.

4. Chiwhane, A., and Pradeep. "Study of Rhythm Disturbances in Acute Myocardial Infarction.” J. Association of Phys. India 66, no. January 2018: 54-58

5. Charan, N., M. Choudhari, M. Sonkusale, and R. Deshpande. "Anesthetic Management of Chronic Thromboembolic Pulmonary Hypertension for Pulmonary Endarterectomy." Journal of Datta Meghe Institute of Medical Sciences University 12, no. 4 (2017): 289-91.

6. Cladius, S., U. Jadhav, B. Ghewade, S. Ali, and T. Dhamgaye. "Study of Diabetes Mellitus in Association with Tuberculosis." Journal of Datta Meghe Institute of Medical Sciences University 12, no. 2 (2017): 143-47.

7. Bhinder, H.H.P.S., and T.K. Kamble. "The Study of Carotid Intima-Media Thickness in Prediabetes and Its Correlation with Cardiovascular Risk Factors.” Journal of Datta Meghe Institute of Medical Sciences University 13, no. 2 (2018): 79-82.

8. Rathi, N., B. Taksande, and S. Kumar. "Nerve Conduction Studies of Peripheral Motor and Sensory Nerves in the Subjects with 
Prediabetes." Journal of Endocrinology and Metabolism 9, no. 5 (2019): 147-50. https://doi.org/10.14740/jem602

9. Berger $\mathrm{J}$ et al. Right arm involvement and pain extension can help to differentiate coronary diseases from chest pain of other origin: a prospective emergency ward study of 278 consecutive patients admitted for chest pain. J Intern Med. 1990;227(3):16572.

10. Goodacre $\mathrm{S}$ et al. How useful are clinical features in the diagnosis of acute, undifferentiated chest pain? Acad Emerg Med. 2002;9(3):203-8.

11. Mittleman $\mathrm{M}$ et al. Triggering of acute myocardial infarction onset by episodes of anger. Determinants of Myocardial Infarction Onset Study Investigators. Circulation. 1995;92(7):1720-5.

12. Tierney W et al. Physicians' estimates of the probability of myocardial infarction in emergency room patients with chest pain. Med Decis Making. 1986;6(1):12-17.

13. Klaeboe $\mathrm{G}$ et al.. Predictive value of prodromal symptoms in myocardial infarction. Acta Med Scand. 1987;222(1):27-30.

14. Herlihy $T$ et al. Nausea and vomiting during acute myocardial infarction and its relation to infarct size and location. Am J Cardiol. 1987;60(1):20-22.
15. Jonsbu $\mathrm{J}$ et al. Rapid and correct diagnosis of myocardial infarction: standardized case history and clinical examination provide important information for correct referral to monitored beds. J Intern Med. 1991;229(2):143-9.

16. Karlson B et al. Early prediction of acute myocardial infarction from clinical history, examination and electrocardiogram in the emergency room. Am J Cardiol. 1991;68(2):171-5.

17. Pozen $M$ et al. A predictive instrument to improve coronarycare-unit admission practices in acute ischemic heart disease. A prospective multicenter clinical trial. N Engl J Med. 1984;310(20):1273-8.

18. Rude R et al. Electrocardiographic and clinical criteria for recognition of acute myocardial infarction based on analysis of 3,697 patients. Am J Cardiol. 1983;52(8):936-42.

19. Yusuf $\mathrm{S}$ et al. The entry ECG in the early diagnosis and prognostic stratification of patients with suspected acute myocardial infarction. Eur Heart J. 1984;5(9):690-6. 